\title{
Tecnologia assistiva na atuação terapêutica ocupacional com uma criança com doença degenerativa do sistema nervoso central ${ }^{1}$
}

\author{
Tácia Caroline de Lima Rodrigues, Juliana Fonsêca de Queiroz Marcelino, \\ Keise Bastos Gomes da Nóbrega
}

Departamento de Terapia Ocupacional, Universidade Federal de Pernambuco - UFPE, Recife, PE, Brasil.

\begin{abstract}
Resumo: Este trabalho tem como objetivo relatar os efeitos das intervenções, utilizando o recurso da tecnologia assistiva, com uma criança com doença degenerativa do sistema nervoso central, em seu domicílio. Trata-se de um estudo de caso, realizado em sete encontros, abordando a criança e seus responsáveis, durante um processo de avaliação, confecção de dispositivos assistivos, orientação da família e avaliação da repercussão no ambiente familiar. Os resultados evidenciaram que a criança apresenta comprometimentos significativos do quadro motor, cognitivo e psicossocial, acarretando em dificuldades na realização de atividades de vida diária, na comunicação e no brincar. Foram propostas adaptações, para favorecer o envolvimento da criança e atenuar as dificuldades da família, nos equipamentos e ambientes, como cadeira de rodas, quarto, banheiro, órtese, brinquedo e comunicação. Por fim, observou-se que os recursos da tecnologia assistiva foram utilizados de acordo com a necessidade e a realidade da criança, e também se pôde constatar que as visitas domiciliares contribuíram positivamente na vida da família ao facilitar o cuidado com a criança, apesar das dificuldades enfrentadas.
\end{abstract}

Palavras-chave: Terapia Ocupacional, Doença Degenerativa do Sistema Nervoso Central, Tecnologia Assistiva.

\section{Assistive technology in occupational therapy practice with a child with degenerative disease of the central nervous system}

\begin{abstract}
This paper aims to report the effects of the interventions, using the resource of assistive technology, carried out with a child with degenerative disease of the central nervous system at his home. This is a study case, which was conducted in seven meetings, addressing the child and his caregivers during a process of evaluation, preparation of assistive devices, family orientation, and evaluation of the family environment repercussion. The results showed that the child presents significant motor, cognitive, and psychosocial impairments, resulting in difficulties in performing activities of daily living, communication, and play. Adjustments were proposed to facilitate the child's involvement and alleviate family difficulties on equipment and environments, such as wheelchair, bedroom, bathroom, orthosis, toys and communication. Finally, it was possible to note that the assistive technology resources were used according to the child's needs and his own reality, and that the domiciliary visits contributed positively to the family's life because they facilitated the child's care, despite the limitations faced.
\end{abstract}

Keywords: Occupational Therapy, Degenerative Disease of the Central Nervous System, Assistive Technology.

Autor para correspondência: Tacia Caroline de Lima Rodrigues, Departamento de Terapia Ocupacional, Universidade Federal de Pernambuco, Rua Prof ${ }^{\circ}$ Moraes Rego, 1235, Cidade Universitária, CEP 50670-901, Recife, PE, Brasil, email: tacia05@hotmail.com

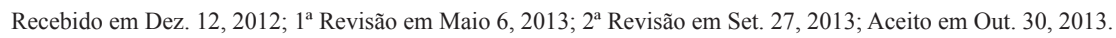

${ }^{1}$ Em memória da criança participante do estudo. 


\section{Introdução}

Terapeutas ocupacionais fundamentam a sua prática na compreensão de que a participação em ocupaçóes e atividades positivas, em casa, na escola, no trabalho e na vida comunitária, estrutura a vida cotidiana, contribui para a saúde e para o bem-estar dos indivíduos. Com isso, a intervenção terapêutica ocupacional propóe auxiliar o indivíduo no desempenho de habilidades física, mental e de bem-estar social, a identificar e perceber aspirações, satisfazer suas necessidades e a modificar ou lidar com o ambiente (AMERICAN..., 2008).

De acordo com os autores supracitados, contextos e ambientes influenciam a acessibilidade e a qualidade do desempenho das ocupaçôes dos indivíduos. Assim, muitas vezes, o ambiente físico, social e o contexto precisam ser modificados para que indivíduos possam desempenhar suas atividades ocupacionais de forma mais efetiva.

Um fator que direciona a intervenção desse profissional diretamente no ambiente físico e social dos indivíduos é que ele está preparado tanto para compreender quanto para intervir nas dificuldades relacionadas à realização de atividades do cotidiano, como nas Atividades de Vida Diária (AVD) e nas Atividades Instrumentais de Vida Diária (AIVD), podendo realizar adaptaçóes no ambiente, utensílios e meios de locomoção para os indivíduos que necessitem. Além disso, desenvolvem atividades voltadas para a inserção e reinserção dos indivíduos na sociedade, no mercado de trabalho e na escola, como também desenvolvem grupos de atenção aos cuidadores e familiares de pessoas com deficiência (NEISTADT, 2002; OLIVER; ALMEIDA, 2007).

E por o ambiente apresentar influência na vida do indivíduo, Hagedorn (2003) afirma que os terapeutas ocupacionais devem reconhecer os efeitos positivos ou negativos desse ambiente, analisar o conteúdo do ambiente, para prover informação sobre as causas dos problemas, implicaçôes referentes ao comportamento e sugestôes para as modificações terapêuticas. Como também essa análise seria uma forma de reduzir custos e tempo nas internaçôes hospitalares, além de propiciar um atendimento mais humanizado com a assistência de uma equipe de saúde (SANTOS; TONIOLO, 2003, p. 245).

Dentre as doenças que podem ocasionar alguma dificuldade na realizaçáo de atividades cotidianas pelo indivíduo estão as Doenças Degenerativas do Sistema Nervoso Central (DDSNC), que são compostas por um grupo de desordens, hereditárias ou adquiridas, que podem ocorrer por alteraçóes estruturais ou neuroquímicas dentro do sistema nervoso central (COPPERMAN; FORWELL; HUGOS, 2005; ZANOTELLI et al., 2007).

Essas desordens, em sua maioria, têm como característica em comum o caráter degenerativo, marcado pela piora progressiva do quadro motor e, além disso, depressão concomitante e déficits cognitivos em razão da destruição de estruturas neurológicas, comprometendo as áreas e componentes de desempenho do indivíduo, que perde sua autonomia e independência para realização das AVD (HASSUI, 2003; SCHULTZ-KROHN; FOTI; GLOGOSKI, 2005).

No tratamento reabilitacional das DDSNC, a atuação do terapeuta ocupacional deverá proporcionar atividades que visem à manutenção do quadro motor, amplitude de movimento e força muscular dos membros superiores. Bem como deverá intervir nas implicaçóes cognitivas, sociais e emocionais do indivíduo. Para isso, deverão ser realizadas orientaçôes sobre a dinâmica familiar e sobre os aspectos psicoafetivos (SCHULTZ-KROHN; FOTI; GLOGOSKI, 2005; ZANOTELLI et al., 2007).

Além disso, o terapeuta ocupacional é um profissional que pode atuar no domicílio, onde são realizadas as atividades diárias do paciente. A atuaçâo é feita pela observação do ambiente do paciente, o envolvimento dele com as tarefas e seus significados, como também identificar seus hábitos e se há algum comprometimento nas habilidades motora, cognitiva e social. O objetivo do tratamento é fazer com que o paciente realize suas atividades cotidianas com autonomia e independência (CAVALCANTI; GALVÃO; QUEIROZ, 2007).

Quando houver declínio gradual e progressivo da capacidade funcional nesta doença, pode-se utilizar de dispositivos da tecnologia assistiva (TA), que é uma área do conhecimento, de característica interdisciplinar, que engloba produtos, recursos, metodologias, estratégias, práticas e serviços que objetivam promover a funcionalidade, relacionada à atividade e participação de pessoas com deficiência, incapacidades ou mobilidade reduzida, visando sua autonomia, independência, qualidade de vida e inclusão social (BRASIL, 2007; FARIA, 2007).

A tecnologia é considerada assistiva quando é usada para auxiliar no desempenho funcional de atividades, reduzindo incapacidades para a realizaçấo de AVD e AIVD, nos diversos domínios do cotidiano. A TA envolve tanto a tecnologia concreta (o equipamento ou instrumento) quanto 
o conhecimento requerido no processo de avaliaçáo, criação, escolha e prescrição, tais como órteses, próteses, equipamentos para mobilidade e equipamentos para comunicação alternativa (MELLO, 1997; ROCHA; LUIZ; ZULIAN, 2003; TEIXEIRA; ARIGA; YASSUKO, 2003).

De acordo com o Conselho Federal de Fisioterapia e Terapia Ocupacional (CONSELHO..., 2006), resoluçáo $\mathrm{n}^{\circ} 316$, do Artigo $2^{\circ}$ de 19 de julho de 2006, é competência do terapeuta ocupacional o uso da tecnologia assistiva nas AVD e AIVD para a inclusão social e o desempenho funcional dos indivíduos, minimizando as desvantagens e potencializando suas habilidades.

Dentre os recursos assistivos, incluem-se sistema de CAS (Comunicação Alternativa e Suplementar); informática acessível; equipamentos para visão e audição; controle do ambiente; AVD; adaptaçáo de jogos, brinquedos e atividades lúdicas; adequação postural em pé e sentado; adaptação ambiental; dispositivos de mobilidade e locomoçáo (REIS, 2004).

A TA pode ser de alta tecnologia, quando engloba equipamentos sofisticados que necessitam de controle de computador ou eletrônico, tais como vocalizadores e sistemas de controle ambiental. Como também de baixa tecnologia, que são aqueles equipamentos ou recursos com pouca sofisticação e confeccionados com materiais de baixo custo disponíveis no dia a dia. Esses equipamentos são produzidos de maneira individualizada (ANSON, 2005; BRACCIALLI, 2007).

O terapeuta ocupacional na TA realiza avaliaçóes das habilidades e condiçôes físicas, cognitivas e sensoriais, de acordo com a necessidade de cada indivíduo, como também verifica a aceitação quanto à modificação ou uso da adaptação, seu aspecto sociocultural e o contexto ambiental em que o usuário utilizará essa adaptação (RIBEIRO, 2007). Cabe ao terapeuta ocupacional instruir a utilização adequada do recurso, orientar os familiares e/ou cuidadores envolvidos nesse contexto, como também estimular a função e maximizar a realização de atividades funcionais (PELOSI; NUNES, 2009).

\section{Objetivo}

Relatar os efeitos das intervençóes, utilizando o recurso da tecnologia assistiva, com uma criança com doença degenerativa do sistema nervoso central, em seu domicílio, por meio de avaliação, confecção dos dispositivos e orientaçôes à família quanto ao uso.

\section{Material e métodos}

\subsection{Tipo de estudo}

Trata-se de um estudo descritivo, do tipo estudo de caso, que segundo Gil (1991) é quando envolve o estudo profundo e exaustivo de um ou poucos objetos de maneira que se permita o seu amplo e detalhado conhecimento. Foram seguidas algumas premissas da metodologia da pesquisa-açáo, no que se refere ao estímulo à participação das pessoas envolvidas, de forma a incentivar os participantes a buscarem e a produzirem sua própria percepção do conhecimento (MELO NETO, 2003, p. 2).

O estudo está vinculado ao projeto pesquisa-ação Terapia Ocupacional na Atenção Básica, desenvolvido na USF (Unidade de Saúde da Família) Sítio Wanderley, na comunidade de Brasilit (bairro da Várzea), localizada no Distrito Sanitário IV, na cidade do Recife, PE.

\subsection{Critério de inclusão}

A criança foi incluída no estudo por apresentar dependência em todas as atividades de vida diária, produtivas e de lazer. A partir disso, foi encaminhada para atendimento de terapia ocupacional por ter necessidade de intervençôes com tecnologia assistiva e por ter dificuldade de acesso aos serviços na rede de saúde.

\subsection{Apresentação do caso clínico}

Vinícius (nome fictício), 11 anos de idade, sexo masculino. Reside na comunidade de Brasilit (bairro da Várzea), em casa própria, com seus pais e uma irmã mais velha. A mãe relatou que Vinícius começou a apresentar, a partir dos 5 anos de idade, pavor a ruídos excessivos, convulsôes e quedas frequentes, progredindo para perda da marcha, da fala, da memória e do controle dos esfíncteres. Aos 8 anos, as dificuldades na mastigação e na deglutição foram intensificadas, sendo necessária a alimentação apenas pastosa e a utilizaçáo de espessante para o líquido (sic mãe). Apresenta uma doença degenerativa do sistema nervoso central, com perda de substância branca e redução volumétrica do encéfalo, com hipótese de ser uma doença genética, porém sem diagnóstico fechado. Parou de frequentar a escola aos 7 anos de idade, devido aos comprometimentos motores e cognitivos. Exames realizados recentemente (Mapeamento da Retina e Potencial Evocado Auditivo 
de Tronco Encefálico - PEATE) demonstraram que a visão e a audição estão preservadas. Realiza fisioterapia motora, respiratória e aquática numa clínica-escola privada da cidade do Recife, fonoaudiologia e terapia ocupacional numa Organização Não Governamental (ONG), estando esta última suspensa no período da pesquisa (licença da terapeuta). Recebe acompanhamento neurológico numa instituiçáo filantrópica especializada no atendimento a crianças com sequelas neurológicas.

\subsection{Procedimento para coleta e análise de dados}

Os dados foram coletados pelas pesquisadoras (uma docente do curso de Terapia Ocupacional e duas acadêmicas) durante as intervençóes que ocorreram a partir de visitas domiciliares, nas quais foram abordadas a criança e seu(s) responsável(is), em 7 encontros, uma vez por semana, com duração de 45 minutos, no período de 2 meses (de agosto a setembro de 2011).

No primeiro encontro, foi apresentado o Termo de Consentimento Livre e Esclarecido (TCLE), o qual foi lido, esclarecido e assinado pelas partes envolvidas. Ainda nesta visita, foram utilizados um questionário elaborado previamente pelas pesquisadoras e um diário de campo, para o registro de informaçóes relevantes para a pesquisa, bem como do ambiente e dos dispositivos assistivos encontrados.

O questionário continha as seguintes variáveis: dados da criança, do cuidador, da residência, dados clínicos e desempenho funcional da criança. Este último subdivide-se em AVD, AIVD, vida social e lazer e dispositivos assistivos.

Na segunda visita, foi finalizada a avaliação da criança e foram solicitados os dispositivos assistivos de que a criança já dispóe. Depois, foram discutidas, entre as pesquisadoras e o(s) responsável(is), as maiores necessidades da criança para melhorar a sua qualidade de vida e de sua família. Traçadas as prioridades, as pesquisadoras confeccionaram alguns dispositivos assistivos, na universidade, para auxiliar a criança em atividades, como no banho, na alimentaçáo e no brincar. Posteriormente, ocorreram outros 5 encontros, para demonstrar e orientar a família quanto ao uso desses dispositivos.

Ao final das intervençôes foi realizada uma entrevista semiestruturada com a genitora, com o objetivo de investigar as repercussóes das intervençôes terapêuticas ocupacionais, por uma pessoa não participante desse processo, a fim de minimizar constrangimentos e interferências nas respostas.
Utilizou-se o termo "adaptaçóes" na entrevista, em lugar de "dispositivos assistivos", para facilitar a compreensão da entrevistada. A entrevista foi gravada e posteriormente transcrita.

Os dados foram analisados de forma qualitativa, por meio da técnica de Condensaçáo de Significados que, conforme Kvale (1996), se baseia no resumo dos significados encontrados no conteúdo das entrevistas, em um formato sucinto, sem perder a sua particularidade.

\section{Considerações éticas}

Esta pesquisa está vinculada ao projeto de pesquisa-ação "Terapia Ocupacional na Atenção Básica”, aprovado pelo edital PROEXT/PROACAD/PROPESQ/ n. 01/2010 - Apoio Financeiro e Bolsas a Projetos de Pesquisa-Ação, aprovado pelo Comitê de Ética em pesquisas em Seres Humanos da Universidade Federal de Pernambuco (registro n. 441/10).

\section{Resultados e discussões}

Durante a avaliação da criança, foi identificado o comprometimento das seguintes funçóes e habilidades de desempenho, conforme AOTA (AMERICAN..., 2008), na Tabela 1, a seguir.

$\mathrm{O}$ quadro clínico de Vinícius corresponde às características clínicas de doenças degenerativas do sistema nervoso central, nas quais, segundo Johnston (2009), ocorrem deteriorização progressiva da função neurológica com perda, algumas vezes, da fala, visão, audição, locomoção, e crises epiléticas, dificuldades na alimentação e comprometimento do intelecto. A idade de início, a velocidade de progressão e os principais achados neurológicos determinam se a doença afeta primariamente a substância branca ou a cinzenta.

Tendo em vista as limitaçóes funcionais da criança, a partir da avaliação foram traçadas algumas prioridades no planejamento dos dispositivos assistivos. Cabe ressaltar que os atendimentos terapêuticos ocupacionais foram realizados no ambiente domiciliar, no qual a assistência para pacientes crônicos visa à promoção, manutenção, restabelecimento da saúde, ou busca da minimização das implicaçôes das doenças e suas incapacidades. Por estar mais próximo do ambiente e da rotina da criança, esse tipo de intervenção torna-se mais eficaz (SANTOS; TONIOLO, 2003).

Ainda no processo de avaliação foram observados os ambientes da casa mais frequentados pela criança (a sala, o quarto e o banheiro), bem como 
Tabela 1. Funções e habilidades de desempenho.

\begin{tabular}{ll}
\hline $\begin{array}{l}\text { Funções } \\
\text { neuromusculoesqueléticas e } \\
\text { relacionadas ao movimento }\end{array}$ & $\begin{array}{l}\text { Oral motora: restrição por alimentação pastosa e líquida com espessante } \\
\text { Óculo-motora: dificuldade na fixação visual } \\
\text { Alinhamento e controle postural } \\
\text { Tônus muscular (espasticidade) }\end{array}$ \\
Habilidades práxica e motora & $\begin{array}{l}\text { Realiza alcance e preensão de um brinquedo mais com o membro superior } \\
\text { direito }\end{array}$ \\
Funções mentais & $\begin{array}{l}\text { Nível de alerta, de consciência e orientação, percepção e atenção, } \\
\text { identificadas pela pouca compreensão das palavras e de comandos simples, } \\
\text { como "pisque os olhos" e pelo desinteresse pelos brinquedos apresentados } \\
\text { Ausência de ações ou comportamentos para iniciar atividades }\end{array}$ \\
$\begin{array}{l}\text { Habilidades cognitivas } \\
\text { Habilidades sociais e de } \\
\text { comunicação }\end{array}$ & $\begin{array}{l}\text { Pouca interação com o ambiente e com a família por causa da dificuldade } \\
\text { nas formas de comunicação verbal e não verbal, realizando apenas por } \\
\text { choro, sorriso e emitindo alguns sons }\end{array}$ \\
\hline
\end{tabular}

foram vistos os equipamentos, órteses que possuía (cadeira de rodas e abdutor de polegar com barra sem articulação) e utensílios utilizados para a realização de AVD. A partir disso, foi realizado o planejamento, confecção e orientação quanto ao uso de algumas adaptaçóes, que se caracterizam como sendo um ramo da tecnologia assistiva, que se define como a modificação da tarefa, método e do meio ambiente, considerando alguns aspectos como tamanho ajustável, custo, conforto e adequação do indivíduo a uma nova situação (TEIXEIRA; ARIGA; YASSUKO, 2003; CAVALCANTI; GALVÃO, 2007). A Tabela 2 descreve a situação encontrada, as adaptaçóes e orientaçóes realizadas e a resposta da família.

A mãe foi orientada quanto à importância da adequação postural sentada na cadeira de rodas, para prevenção de deformidades e funcionalidade, visto que, na maioria das visitas, a criança foi encontrada deitada no sofá, encostada em algum familiar. Surgindo, dessa forma, uma contradição entre as respostas da família, em relação à aceitação no número da frequência e de tempo na $\mathrm{CR}$ e sobre a criança não estar posicionada nela durante a maioria das visitas. Segundo Chaves, Rizo e Alegretti (2003), a cadeira de rodas deve ser confortável e aliviar os pontos de pressão, pois a pessoa passará grande parte de seu tempo nesse equipamento, deve otimizar e maximizar as funçôes motoras e funçôes fisiológicas, como facilitar a deglutição, digestão e respiraçáo, proporcionar suporte corporal e permitir alteraçôes e ajustes de acordo com as necessidades do indivíduo. Também foi percebido que Vinícius permanecia muito tempo deitado no sofá.

A criança utiliza as órteses de membros superiores (abdutor de polegar com barra sem articulação) durante o dia todo (sic mãe), exceto no momento do banho. As órteses de membros inferiores não eram utilizadas, por já estarem pequenas para Vinícius.
Segundo Rodrigues, Cavalcanti e Galvão (2007), a órtese é um dispositivo que tem a finalidade de possibilitar a função por meio da aplicação ou diminuição de forças sobre o corpo, para proteger a cicatrização de estruturas; da manutenção para prevenir ou corrigir deformidades; e da substituição ou aumento de uma função.

Vinícius apresenta dificuldade nas formas de comunicação, verbal e não verbal, portanto foi pensado, pelas pesquisadoras, a utilização do recurso de Comunicação Alternativa e Suplementar (CAS), que tem a finalidade de compensar a inabilidade ou a deficiência do indivíduo com alguma disfunção de comunicação significativa, verbal ou escrita, permanentemente ou por um período determinado (PELOSI, 2007).

Com isso, foi avaliada a possibilidade de a criança realizar a "comunicaçáo visual", ou seja, se expressar através do olhar. Segundo Cassemiro e Arce (2004), através do piscar dos olhos é possível expressar pensamentos e sentimentos. Contudo, como as respostas da criança não foram suficientes, bem como ela não apresentou fixação do olhar, não pôde ser implementada a CAS.

Foi observado que Vinícius não possuía nenhum brinquedo, sendo privado de experiências de ensino-aprendizagem e de lazer. Sabe-se que o brincar proporciona recompensas comportamentais, sociais e psicomotoras. Além disso, promove mudanças, constrói a inteligência por meio da experimentação de desafios, investigaçáo, resolução de problemas, favorece a interação da criança com o ambiente, contribuindo assim com o desenvolvimento de estruturas neurais (HOLLOWAY, 2000; VYGOTSKY, 1987).

O comprometimento cognitivo da criança é característico dessa doença degenerativa, que, segundo Johnston (2009), repercute na ineficiência ou inabilidade para processar informaçóes e 


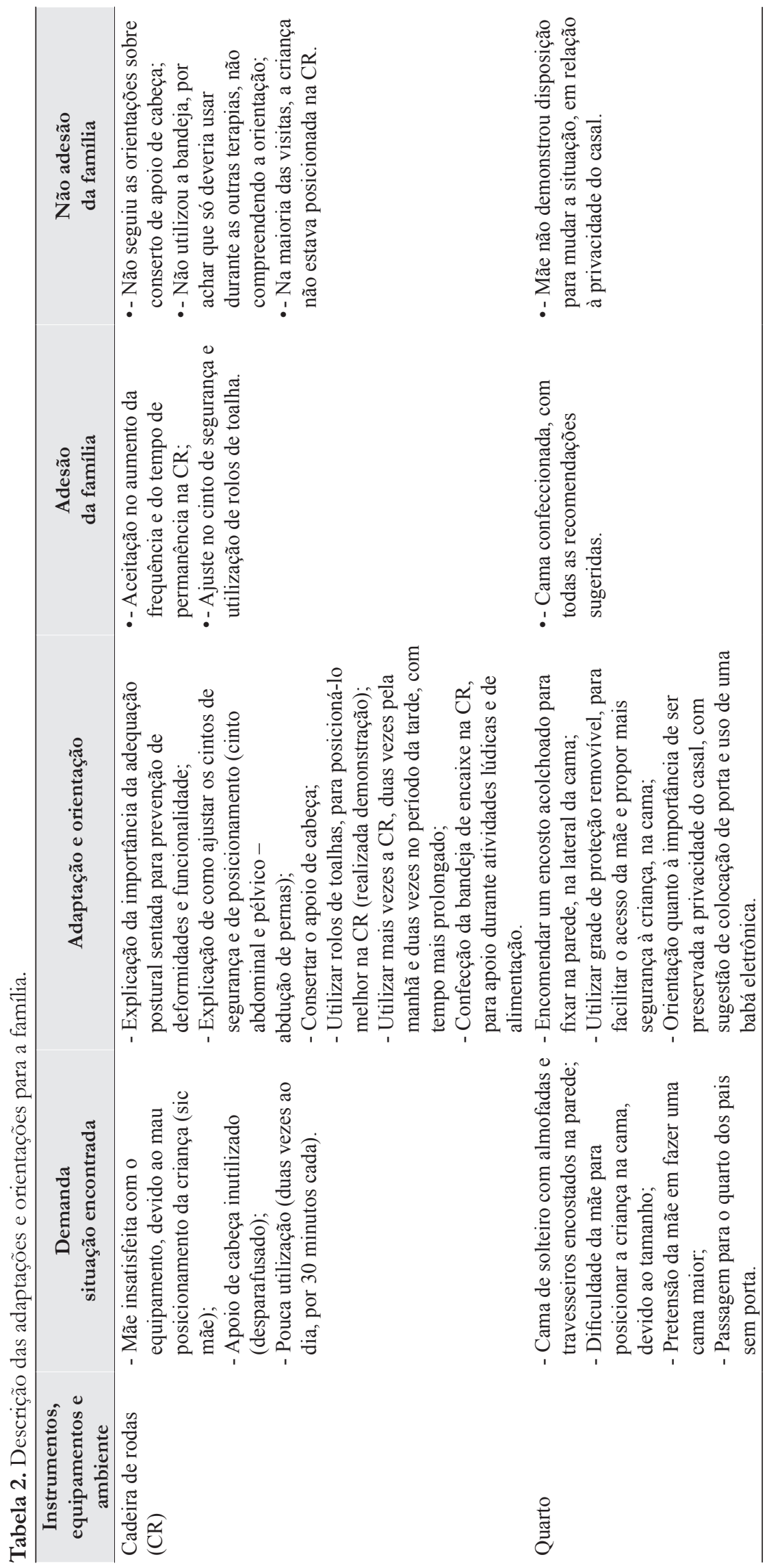




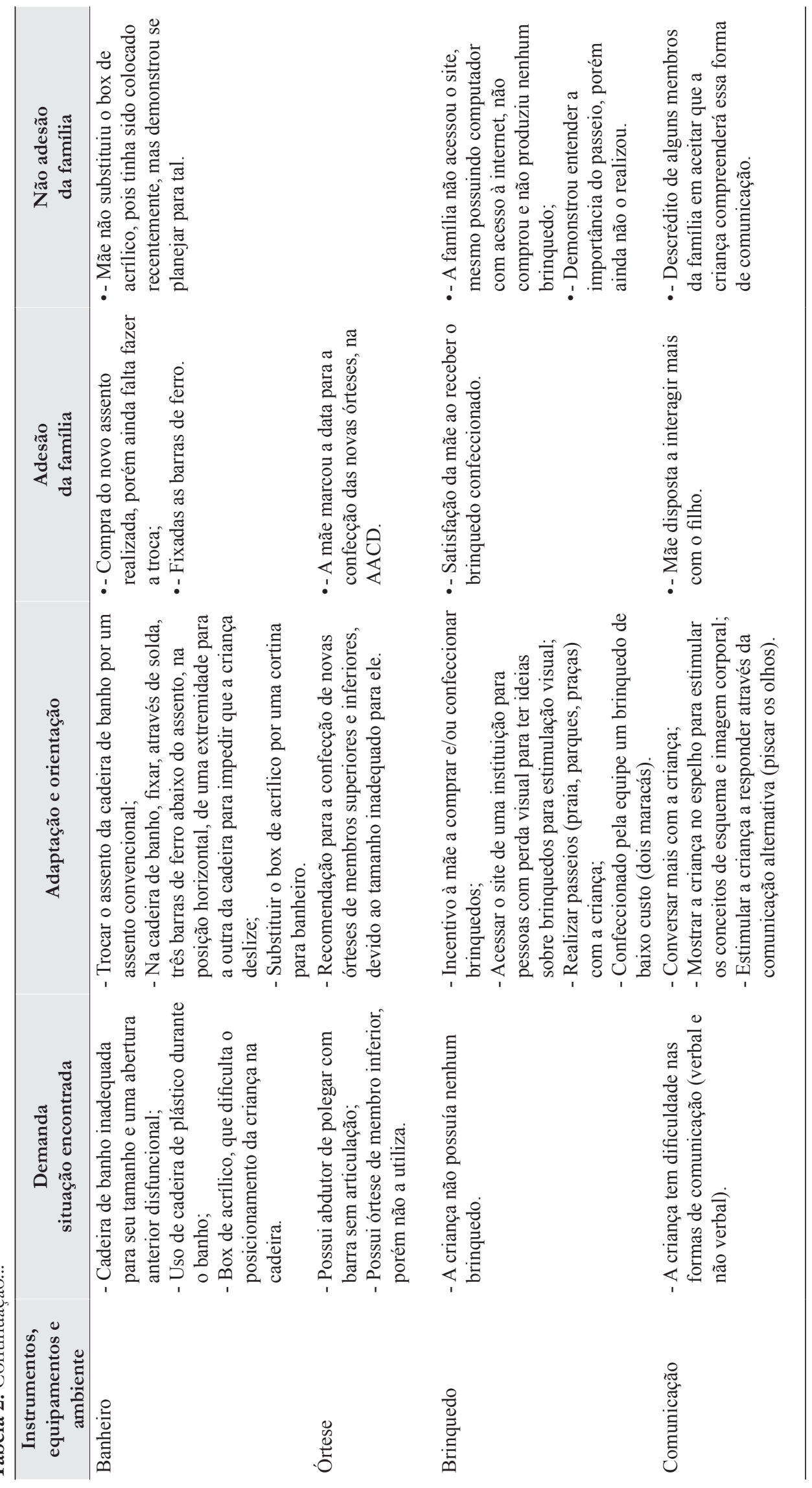


para envolver-se com o ambiente. Esses aspectos influenciaram negativamente no desenvolvimento de Vinícius, inclusive no brincar, pois ele não dá funcionalidade ao brinquedo. Por isso, é necessária a participação da família na promoção de estímulos relevantes e, consequentemente, isso irá melhorar a relação familiar.

Dessa maneira, orientou-se a família para introduzir o brincar na rotina da criança, com atividades lúdicas que visam melhorar o desempenho motor, social e cognitivo, e que também proporcionassem bons momentos de interação familiar (HOLLOWAY, 2000). Para incentivar a criança a brincar, utilizando estímulos visuais e sonoros, foram produzidos pelas pesquisadoras dois maracás (Figura 1), utilizando garrafa pet (tamanho pequeno), tubos de PVC, arroz e feijão, para fazer o som do chocalho, e durex colorida, de cores contrastantes, para decorar.

Outra forma de envolver Vinícius no brincar foi o planejamento e a confecção de uma bandeja com inclinação removível (Figura 2), para encaixar na cadeira de rodas, com o objetivo de estimulá-lo em atividades lúdicas, como desenhar e pintar, bem como para proporcionar apoio na atividade de alimentação para os cuidadores. Essa bandeja foi confeccionada utilizando papeláo, papel contato preto e velcro, para fixar a mesa no braço da cadeira.

O uso de papeláo e tubos de PVC tem possibilitado a confecção de equipamentos adaptados para pacientes com alguma disfunção neuromotora, pois as vantagens de usá-los englobam seu baixo custo, rápida fabricação e fácil manipulação. Esses materiais permitem criar adaptaçôes duráveis, leves e desenhadas de acordo com as necessidades específicas de cada pessoa (MAIA et al., 2008; GASPARINI, 2008).

\subsection{Percepção da mãe quanto à intervenção terapêutica ocupacional}

Através da entrevista semiestruturada, foi possível analisar a percepção da mãe a respeito da intervenção terapêutica ocupacional realizada. No que se refere à diferença na vida da criança após os encontros, a mãe relatou que houve melhora, principalmente para a sua vida, por causa das orientaçóes. Ao questionar se as adaptaçōes e orientaçóes interferiram na rotina familiar, a mãe afirmou que facilitou o cuidado.

Indagada sobre as adaptaçóes mais utilizadas, a mãe se referiu à cama e à cadeira de rodas, e sobre as orientaçôes mais seguidas, citou como posicionar a criança ao sentar e como dar as refeiçốes. A criança

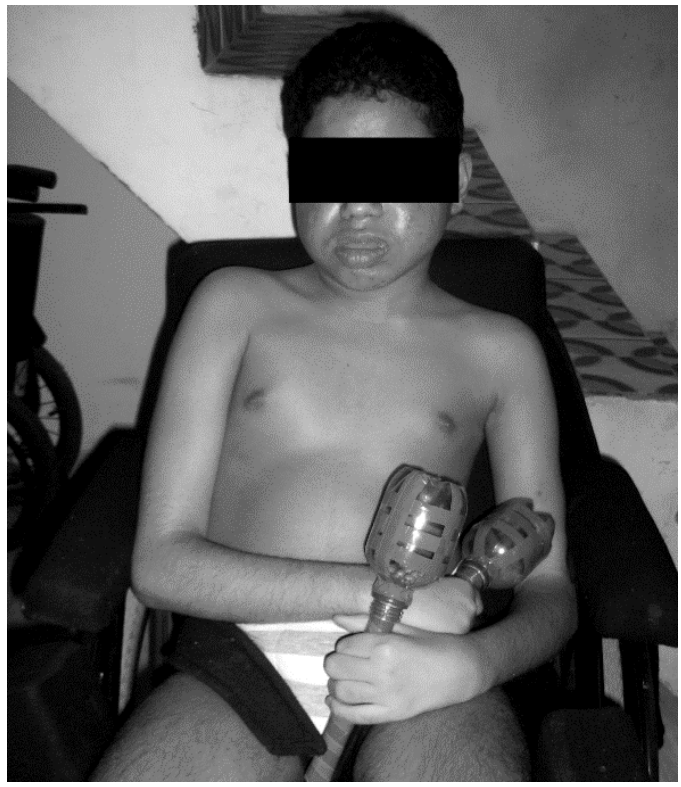

Figura 1. Maracás confeccionados.

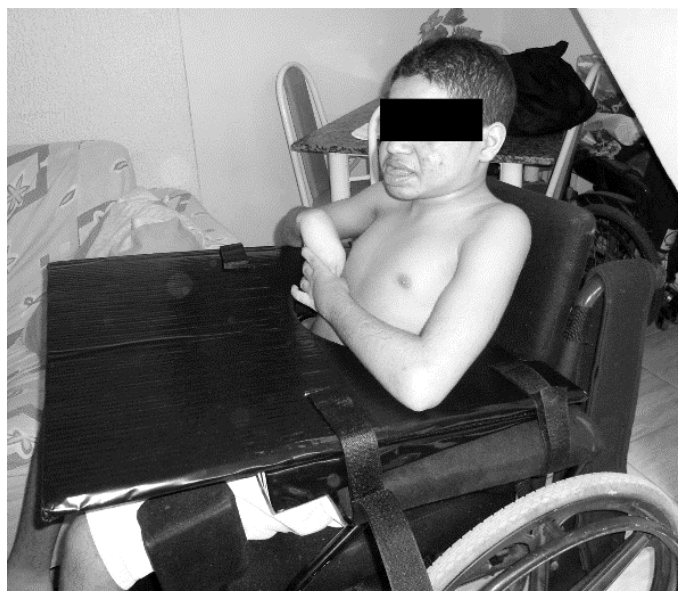

Figura 2. Bandeja com inclinação removível.

possuía uma cadeira de rodas, que só foi utilizada com mais frequência após as visitas, e a cama foi adaptada para ter um maior conforto.

Questionada sobre o surgimento de limitaçóes e dificuldades durante o processo de intervenção, a mãe negou essa possibilidade. E em relação à necessidade de retorno da equipe de terapia ocupacional para dar mais orientaçôes, à necessidade de outras adaptaçóes, a mãe expôs que esse retorno seria bom, por causa dos esclarecimentos, apesar de não ter mais nenhuma dúvida, e que sente a necessidade de uma adaptação para a alimentação.

Por fim, ao perguntar se ela se sentia mais preparada para realizar adaptaçóes sem o auxílio da 
equipe, a mãe mostrou-se insegura e afirmou náo ver necessidade de confeccionar nenhuma adaptação.

Foi firmado um compromisso com a máe de retorno da equipe de terapia ocupacional, para responder a possíveis dúvidas a respeito da intervenção em tecnologia assistiva e para a análise das possibilidades de adaptaçôes para a alimentação.

\section{Considerações finais}

A partir das visitas domiciliares, foram constatados comprometimentos nas funçôes e habilidades de desempenho da criança e evidenciou-se que as intervençóes contribuíram positivamente na vida da família ao facilitar o cuidado com a criança.

Observou-se que a família busca condiçôes melhores de vida para a criança, considerando a rotina da mãe de levar o filho às terapias, o investimento realizado em órteses, a adaptação da cadeira de rodas, bem como a motivação que demonstrava ao receber as visitas da equipe de terapia ocupacional. Contudo, algumas áreas de ocupação da criança parecem não ser prioritárias para a família, como o brincar e o lazer.

Foram identificadas algumas dificuldades para a intervenção em tecnologia assistiva, tais como o grau de comprometimento da criança, a falta de recursos da família e a sobrecarga de trabalho da mãe. Esses fatores também parecem ter influenciado na iniciativa da mãe para confecção das adaptações sugeridas e para seguir algumas orientaçóes.

\section{Referências}

ANSON, D. Tecnologia assistiva. In: PEDRETTI, L. W.; EARLY, M. B. Terapia Ocupacional: capacidades práticas para disfunçôes físicas. São Paulo: Roca, 2005. p. 276-295.

AMERICAN JOURNAL OCUPACCIONAL THERAPY - AOTA. Occupacional therapy practice. Framework: domain \& process. The American Journal Ocupaccional Therapy, Bethesda, v. 63, n. 6, p. 625-683, 2008.

BRACCIALLI, L. M. P. Tecnologia assistiva: perspectiva de qualidade de vida para pessoas com deficiência. In: VILARTA, R. et al. (Orgs.). Qualidade de vida e novas tecnologias. Campinas: IPES, 2007. p. 105-114.

BRASIL. Secretaria Especial dos Direitos Humanos da Presidência da República (CORDE/SEDH/PR). Ata da Reunião do Comitê de Ajudas Técnicas. Brasília, 2007. Disponível em: <http://www.mj.gov.br/sedh/ct/corde/ dpdh/corde/Comitê\%20\%de\%20Ajudas \%20Técnicas/ Ata_VII_Reunião_do_Comite_de_Ajudas_Técnicas. doc>. Acesso em: 12 dez. 2012.
CASSEMIRO, C. R.; ARCE, C. G. Comunicação visual por computador na esclerose lateral amiotrófica. Arquivos Brasileiros de Oftalmologia, São Paulo, v. 67, n. 2, p. 295-300, 2004.

CAVALCANTI, A.; GALVÃO, C. Adaptação ambiental e doméstica. In: CAVALCANTI, A.; GALVÃO, C. Terapia Ocupacional: fundamentaçâo e prática. Rio de Janeiro: Guanabara Koogan, 2007. p. 420-425.

CAVALCANTI, A.; GALVÃO, C.; QUEIROZ, M.E.G. Home care. In: CAVALCANTI, A.; GALVÃO, C. Terapia Ocupacional: fundamentação e prática. Rio de Janeiro: Guanabara Koogan, 2007. p. 508-511.

CHAVES, E. S.; RIZO, L. R.; ALEGRETTI, A. L. Adequaçáo postural para o usuário de cadeira de rodas. In: TEIXEIRA, E. et al. Terapia Ocupacional na reabilitação fisisca. São Paulo: Roca, 2003. p. 175-191.

CONSELHO FEDERAL DE FISIOTERAPIA E TERAPIA OCUPACIONAL - COFFITO. Resolução, n ${ }^{\circ}$ 316, de 19 de julho de 2006. Dispóe sobre a Prática de Atividadede Vida Diária, de Atividades Instrumentais de Vida Diária e Tecnologia Assistiva pelo Terapeuta Ocupacional e dá Outras Providências. Diário Oficial da Uniāo, Poder Executivo, Brasília, DF, 3 ago. 2006.

COPPERMAN, L. F.; FORWELL, S. J.; HUGOS, L. Doenças neurodegenerativas. In: TROMBLY, C. A.; RADOMSKI, M. V. Terapia Ocupacional para disfunçöes fisicas. São Paulo: Santos, 2005. p. 885-888.

FARIA, I. Neurologia adulto. In: CAVALCANTI, A.; GALVÃO, C. Terapia Ocupacional: fundamentação e prática. Rio de Janeiro: Guanabara Koogan, 2007. p. 187-188.

GASPARINI, G. C. Mobiliário adaptado para pacientes com disfunção neuromotora confeccionados em PVCtubos e conexôes. In: OLIVEIRA, A. I. A.; LOURENÇO, J. M. Q.; LOURENÇO, M. G. F. Perspectivas da tecnologia assistiva no Brasil: pesquisa e prática. Belém: EDUEPA, 2008. p. 107-108.

GIL, A. C. Como elaborar projetos de pesquisa. São Paulo: Atlas, 1991.

HAGEDORN, R. Fundamentos para a prática em Terapia Ocupacional. São Paulo: Rocca, 2003.

HASSUI, M. K. Doenças neuromusculares. In: TEIXEIRA, E. et al. Terapia Ocupacional na reabilitação fisica. São Paulo: Roca, 2003. p. 407-428.

HOLLOWAY, E. Como favorecer o entretenimento progenitor-lactente na UTI neonatal. In: PARHAM, L. D.; FAZIO, L. S. A recreação na terapia ocupacional pediátrica. São Paulo: Santos, 2000. p. 171-183.

JOHNSTON, M. V. Distúrbios neurodegenerativos infantis. In: KLIEGMAN, R. M.; NELSON, W. E. N. Tratado de Pediatria. Rio de Janeiro: Elsevier, 2009. p. 2505-2506. 
KVALE, S. Interviews: an introduction to qualitative research interviewing. London-New Deli: Sage Publications, 1996.

MAIA, S. R. et al. Programa parceria com as famílias: mobília adaptada em papelão. In: OLIVEIRA, A. I. A.; LOURENÇO, J. M. Q.; GAROTTI, M. F. Tecnologia Assistiva: pesquisa e prática. Belém: EDUEPA, 2008. p. 61-66.

MELLO, M. Tecnologia Assistiva. In: GREVE, J. M. D.; AMATUZZI, M. M. Medicina de reabilitação aplicada à ortopedia e traumatologia. São Paulo: Manole, 1997. p. 7-14.

MELO NETO, J. F. Pesquisa-ação: aspectos práticos da pesquisa-ação nos movimentos sociais populares e em extensão popular. In: RICHARDSON, R. J. (Org.). Pesquisa-ação: princípios e métodos. João Pessoa: Editora Universitária da UFPB, 2003. p. 1-9.

NEISTADT, M. E. Introdução à avaliação e entrevista. In: CREPEAU, E. B.; CONH, E. S.; SCHELL, B. A. B. Willard e Spackman: Terapia Ocupacional. São Paulo: Guanabara Koogan, 2002. p. 137-152.

OLIVER, F. C.; ALMEIDA, M. C. Reabilitação baseada na comunidade. In: CAVALCANTI, A.; GALVÃO, C. Terapia ocupacional: fundamentação e prática. Rio de Janeiro: Guanabara Koogan, 2007. p. 125-132.

PELOSI, M. B. Comunicação Alternativa e Suplementar. In: CAVALCANTI, A.; GALVÃO, C. Terapia Ocupacional: fundamentação e prática. Rio de Janeiro: Guanabara Koogan, 2007. p. 462-467.

PELOSI, M. B.; NUNES, L. R. O. P. Formação em serviço de profissionais da saúde na área de tecnologia assistiva: o papel do terapeuta ocupacional. Revista Brasileira de Crescimento e Desenvolvimento Humano, São Paulo, v. 19, n. 3, p. 435-444, 2009.
REIS, N. M. M. A Tecnologia Assistiva na paralisia cerebral. In: LIMA, C. L. A.; FONSECA, L. F. Paralisia Cerebral: neurologia, ortopedia e reabilitação. Rio de Janeiro: Guanabara Koogan, 2004. p. 431-446.

RIBEIRO, M. A. Design universal. In: CAVALCANTI, A.; GALVÃO, C. Terapia ocupacional: fundamentação e prática. Rio de Janeiro: Guanabara Koogan, 2007. p. 417-419.

ROCHA, E. F.; LUIZ, A.; ZULIAN, M. A. R. Reflexóes sobre as possíveis contribuiçóes da terapia ocupacional nos processos de inclusão escolar. Revista de Terapia Ocupacional da Universidade de São Paulo, São Paulo, v. 14, n. 2, p. 72-78, 2003.

RODRIGUES, A. V. N.; CAVALCANTI, A.; GALVÃO, C. Órtese e prótese. In: CAVALCANTI, A.; GALVÃO, C. Terapia Ocupacional: fundamentação e prática. Rio de Janeiro: Guanabara Koogan, 2007. p. 435-442.

SANTOS, C. A. F; TONIOLO, J. Home care. In: LEVY, J. A.; OLIVEIRA, A.S.B. Reabilitaçâo em doenças neurológicas: guia terapêutico prático. São Paulo: Atheneu, 2003. p. 245-249.

SCHULTZ-KROHN, W.; FOTI, D.; GLOGOSKI, C. Doenças degenerativas do sistema nervoso central. In: PEDRETTI, L. W.; EARLY, M. B. Terapia Ocupacional: capacidades práticas para disfunçóes físicas. São Paulo: Roca, 2005. p. 739-764.

TEIXEIRA, E.; ARIGA, M. Y.; YASSUKO, R. Adaptaçōes. In: TEIXEIRA, E. et al. Terapia Ocupacional na reabilitação física. São Paulo: Roca, 2003. p. 129-171.

VYGOTSKY, L. S. A formação social da mente. São Paulo: Martins Fontes, 1987.

ZANOTELLI, E. et al. Doenças Neuromusculares. In: FERNANDES, A. C. et al. AACD Medicina e Reabilitação: princípios e prática. São Paulo: Artes Médicas, 2007. p. $115-139$.

\section{Contribuição dos autores}

Tácia Rodrigues: Participação em todas as etapas da pesquisa. Juliana Marcelino: Orientadora da pesquisa, com participação direta no levantamento e discussão dos dados. Keise Nóbrega: Responsável pela revisão do artigo. Todas as autoras aprovaram a versão final do texto. 